\section{Call for ecosystem modelling data}

We call on bioinformaticians, taxonomists and ecologists to collect, store and share new types of data for creating general ecosystem models (GEMs) that will eventually be used for predictive modelling of the biosphere (see G. Mace Nature 503, 191-192; 2013). Funding bodies also need to recognize the importance of this work.

Crucial requirements include: a database of functional traits for different species, which would allow modelling to take advantage of existing information associated with species-based databases; biotic data that indicate how organisms interact through space and time; and census data that quantify the number or weight of organisms in an ecosystem organized by functional traits.

These comprehensive functional data will speed up the development of GEMs by enabling uncertainties to be reduced and predictions to be evaluated (see D. Purves et al. Nature 493, 295-297; 2013).

We therefore appeal to taxonomists, who are usually concerned with morphological traits, to collect information on life histories and behavioural traits, especially with respect to species interactions. Ecologists can also contribute to these enhanced species descriptions by treating individuals as part of assemblages of the same species and as communities of different species, thereby providing valuable collective information.

The technological capacity to store and share trait information is being developed by the Encyclopedia of Life (eol.org/traitbank). This can be scaled up to provide morecomprehensive data, such as those to describe interactions between organisms.

Mike Harfoot United Nations Environment Programme
World Conservation Monitoring Centre, and Microsoft Research, Cambridge, UK.

mike.harfoot@unep-wcmc.org.

Dave Roberts Natural History

Museum, London, UK.

scratchpads@nhm.ac.uk

\section{Halt self-citation in impact measures}

We can improve the gender differences in science publishing and research (see V. Larivière et al. Nature 504, 211-213; 2013) by making measurements of scientific output and impact fairer.

For example, time spent on active research should be incorporated into assessments of research productivity. This would provide a fairer comparison for researchers who take parental leave or who have other caring duties or high teaching loads, and would reduce the pressure on those scientists.

It would also be useful to halt the inclusion of author self-citations in measures of research impact, because selfcitation is a male-biased practice (E. Z. Cameron et al. Trends Ecol. Evol. 28, 7-8; 2013). After all, genuine impact hinges on independent citation.

Elissa Z. Cameron, Amy M. Edwards University of Tasmania, Hobart, Australia.

elissa.cameron@utas.edu.au

Angela M. White US Department of Agriculture Forest Service, Davis, California, USA.

\section{Himalayas already have hazard network}

Maharaj Pandit calls for the protection of the Himalayas through an international network to monitor environmental risks, develop early-warning systems to detect hazards and provide a better understanding of Himalayan geology and ecology (Nature 501, 283; 2013). Such a network is in fact already in place, but it needs more international support if it is to be properly effective.

The International Centre for Integrated Mountain Development (ICIMOD) in Kathmandu, Nepal, was founded 30 years ago by the eight countries of the Hindu KushHimalayan region. ICIMOD's expertise is now internationally recognized (S. Sarkar Himal. J. Sci. 4, 7-8; 2007).

ICIMOD forms a centre for intergovernmental knowledge and learning, as well as for regional research and development. It works for sustainable economic and environmental development of the Himalayan ecosystems, by monitoring risks from glacial lakes and providing early warning of hazards such as forest fires and flooding in many of its member countries.

Furthermore, the formation of a Himalayan University Consortium is strengthening collaboration between universities in the region. ICIMOD has been collaborating with governments, academics and non-governmental and community-based organizations from several Hindu KushHimalayan countries on conservation programmes to identify the most vulnerable transboundary landscape areas, which are also of global importance.

Yadav Uprety, Ram P. Chaudhary Research Centre for Applied Science and Technology, Tribhuvan University,

Kathmandu, Nepal.

yuprety@yahoo.com

Nakul Chettri ICIMOD,

Kathmandu, Nepal.

\section{Avoid pitfalls of consensus methods}

We would like to clarify points raised in William Sutherland's criticism of the treatment of pollinators in the UK National Ecosystem Assessment (Nature 503, 167; 2013).

The estimated economic costs of pollinator decline are only as robust as the natural science on which they rest, as Sutherland indicates. If we could predict with certainty the effects of changes in pollinator populations on agricultural production, then evaluating them would be trivial.

It was because of uncertainty in the underlying population ecology that we omitted estimates of pollination services from our economic analysis of the impacts of land-use change in our report, which was extensively peer-reviewed (see also I. J. Bateman et al. Science 341, 45-50; 2013).

The Delphi technique - a consensus method that Sutherland mentions for synthesizing research findings - can be helpful in some situations, but should be applied with caution to environmental valuation. The rapid expansion of empirical literature in this field means that conventional beliefs can rapidly become groupthink norms, with dangerous consequences.

For example, we rejected the popular consensus in favour of using survey techniques as a way of valuing biodiversity, choosing instead to estimate the costs of ensuring species conservation. We stand by our approach, which we believe conforms with Sutherland's appeal for quality over quantity.

Ian Bateman, Matthew Agarwala, Tomáš Badura University of East Anglia, Norwich, UK. i.bateman@uea.ac.uk

CONTRIBUTIONS Correspondence may be sent to correspondence@ nature.com after consulting the guidelines at http:// go.nature.com/cmchno. Alternatively, readers may comment online: www. nature.com/nature. 